Check for updates

Cite this: Mater. Chem. Front. 2020, 4, 437

Received 5th October 2019 Accepted 28th November 2019

DOI: $10.1039 / c 9 q m 00614 a$

rsc.li/frontiers-materials

\section{A review on the effects of carbon dots in plant systems}

\author{
Yadong Li, (D) Xiaokai Xu, Ying Wu, Jianle Zhuang, (D) Xuejie Zhang, \\ Haoran Zhang, Bingfu Lei, (DD * Chaofan Hu* and Yingliang Liu (D)*
}

\section{Introduction}

Cultivation of plants for food is one of the most critical human endeavors that has taken place in the history of human civilization. Due to the advances in agricultural production technology, the number of undernourished people has roughly halved in the past 20 years. ${ }^{1}$ However, there are almost a billion people still suffering from insufficient nutrition. ${ }^{1}$ In order to

Guangdong Provincial Engineering Technology Research Center for Optical Agriculture, College of Materials and Energy, South China Agricultural University, Guangzhou 510642, China. E-mail: tleibf@scau.edu.cn, thucf@scau.edu.cn, tliuyl@scau.edu.cn feed the continuously increasing population and supply industry, the amount of resources consumed by agriculture is staggering. It has been roughly calculated that over 3 billion metric tons of crops are produced annually in the world, requiring 187 million metric tons of fertilizer, nearly 4 million tons of pesticides, and 2.7 trillion cubic meters of water (about $70 \%$ of all global freshwater consumption). ${ }^{2}$ Ubiquitous and inefficient use of pesticides and herbicides pose a severe threat to biodiversity and the ecosystem and have caused serious resistance to these substances. ${ }^{3,4}$ Furthermore, climate change, such as extreme weather and epidemics involving pests and diseases, is bound to put increasing stress on food production and distribution. ${ }^{5}$ In this context, the agricultural industry urgently requires the

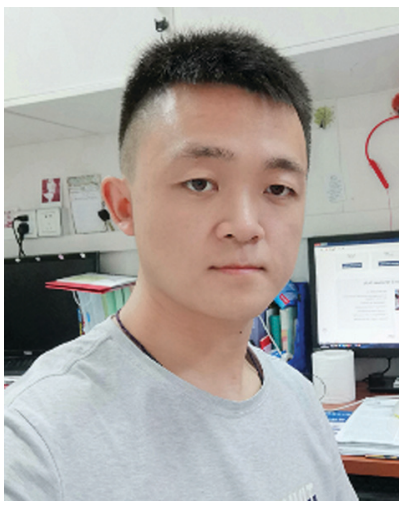

Yadong Li
Yadong $L i$ received his $B S$ degree in 2015 and MS degree in 2018 from Shihezi University. From 2016 to 2018, he did combined training at the Shihezi University and the Guangdong Institute of Eco-environmental Science \& Technology. Currently, he is pursuing a PhD degree in the group of Prof. Yingliang Liu at South China Agricultural University (SCAU). His research interests involve the synthesis and application of specifically functionalized carbon dots in agriculture.

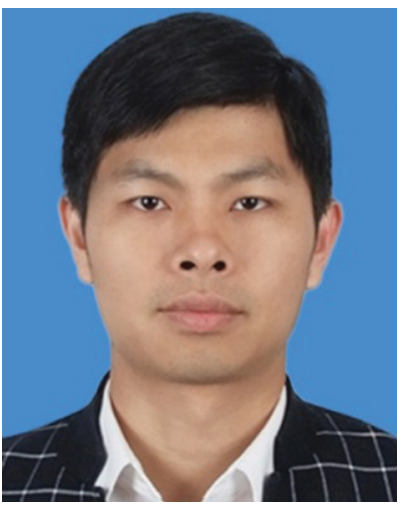

Jianle Zhuang
Jianle Zhuang received his $P h D$ degree in materials physics and chemistry from Sun Yat-Sen University in 2009. During 20112013, he was a postdoctoral fellow at The Hong Kong University of Science and Technology. Currently, he is an associate professor at South China Agricultural University. His research interests focus on the synthesis and application of luminescent materials, including lanthanide-doped nanomaterials, upconversion materials and carbon dots. 
development of new environmentally-friendly technologies to face the challenge of increasing food production.

Nanomaterials are believed to play a key role in addressing these challenges faced by agriculture in the future. Over the past few decades, abundant nanomaterials have been developed and applied in agriculture to monitor crop health, ${ }^{6}$ promote the growth of crops, ${ }^{7-9}$ improve the efficiency of fertilizer and pesticides, ${ }^{10,11}$ and manage diseases,${ }^{12}$ pests, ${ }^{13}$ and environmental stresses. ${ }^{14}$ Compared to other metal-based nanomaterials, carbon-based nanomaterials show much lower environmental toxicity and higher biocompatibility due to their non-toxic carbon backbone. ${ }^{15-17}$ Thus, carbon-based nanomaterials have been widely applied in agriculture. ${ }^{18-20}$ As a novel member of the carbon nanomaterial family, carbon dots (CDs) possess a size of less than $10 \mathrm{~nm}$ and have inherent photoluminescence (PL) properties. In recent years, CDs have been the focal point of interest for many researchers, since they have superior and universal properties, including excellent photostability, small size, biocompatibility, water solubility, highly tunable PL properties, easy functionalization with biomolecules and chemical inertness. $^{21,22}$ Although it is not very long since the discovery of CDs in 2004, carbon quantum dots (CQDs) have been the subject of numerous optical research studies, for use in areas such as biomonitoring, sensing, photocatalysis, drug and gene delivery, solar energy conversion and LEDs. ${ }^{23}$ What is more, CDs have been considered as alternatives to conventional semiconductor quantum dots in order to overcome their toxicity and environmental concerns. ${ }^{24}$

Since the biocompatibility of CDs with bean sprouts was revealed by Qu et al., ${ }^{25}$ the potential effects that CDs have on various crop plant growth have attracted more and more attention from researchers worldwide. Up to now, superior performance of CDs in several physiological processes of plants has been demonstrated, including growth, photosynthesis, and resistance to abiotic/biotic stress. ${ }^{26-28}$ Additionally, CD treatments has also shown enhanced effects of the biological nitrogen fixation by azotobacter. ${ }^{29}$ Furthermore, CDs play a role in the delivering of siRNA in a model plant and the in situ imaging of environmental pollutants. ${ }^{30,31}$ Nevertheless, there is no review that focuses on the biological functions of CDs in the

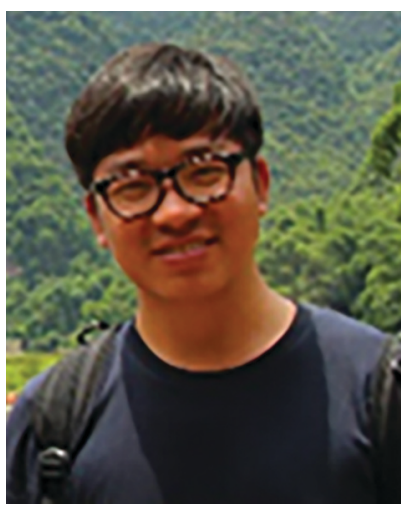

Xuejie Zhang
Xuejie Zhang is currently an associate professor at the college of materials and energy in South China Agricultural University (SCAU). He obtained his BS degree from the Zhoukou Normal University in 2010 and was a graduate student at the Sun Yat-sen University, and received a PhD degree in 2015. After graduation, he worked as a postdoctoral researcher at Taiwan University for one year. His current research interests include phosphors and luminescent glass-ceramic materials together with their applications in displays and lighting.

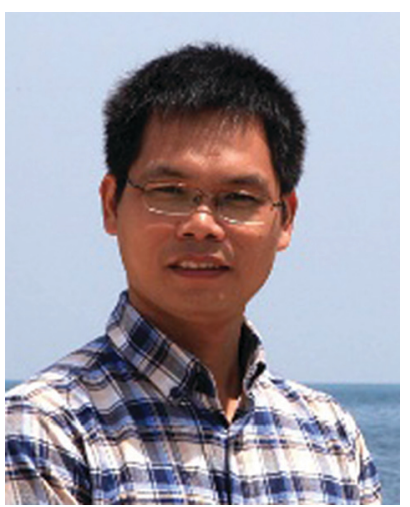

Bingfu Lei
Bingfu Lei is a professor at the college of materials and energy at South China Agricultural University (SCAU). He received his $B S$ and $M S$ from the department of chemistry at Jinan University (JNU), and the PhD degree at Changchun Institute of Optics, Fine Mechanics and Physics, Chinese Academy Sciences. After graduation, he worked as a postdoctoral fellow (JSPS) at Osaka University for two years. His research interests include phosphors, carbon dots, and silicon dots materials together with their applications in plant growth, lighting, biolabeling, and sensing. He has published more than 300 peer-reviewed journal articles in related fields.

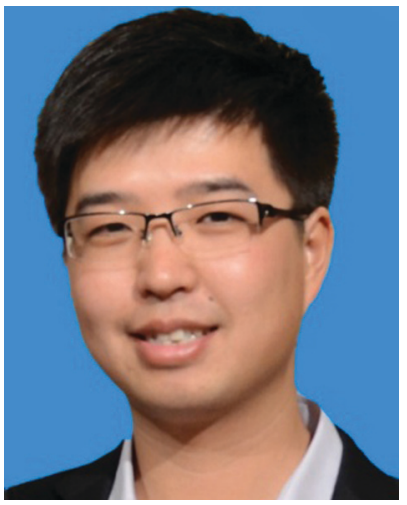

Chaofan Hu
Chaofan Hu received his BS degree from Hebei Polytechnic University in 2007 and MS degree from South China Normal University in 2010 and obtained his $P h D$ degree from Jinan University in 2013 and then joined Taiyuan University of Technology as a lecturer. Currently, he is an associate professor at South China Agricultural University. His research interests include the synthesis of luminescent nanomaterials and their bio-applications.

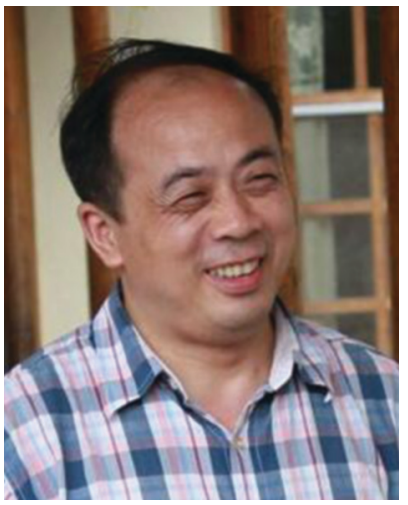

Yingliang Liu received his master's degree from Changchun Institute of Applied Chemistry, Chinese Academy of Sciences in 1989 and his doctor's degree from Zhongshan University in 1994. He has engaged in research on carbon quantum dots and their agricultural applications. 

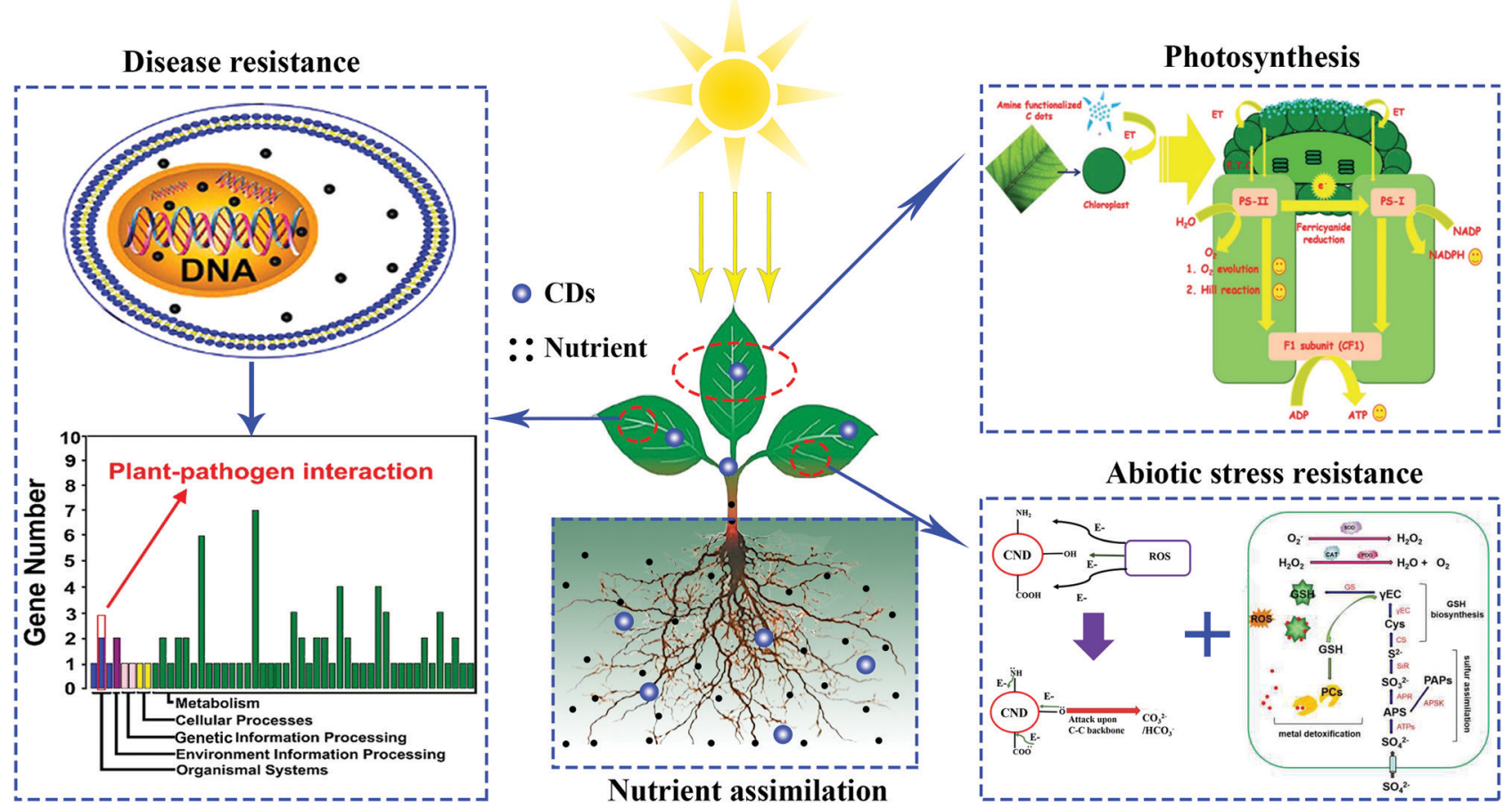

Abiotic stress resistance

Fig. 1 Different applications of CDs in agriculture. ${ }^{28,60,69,74}$ Reprinted with permission from the American Chemical Society, Copyright 2018 (ref. 28); the Royal Society of Chemistry, Copyright 2014 (ref. 60 and 69); Elsevier, Copyright 2019 (ref. 74).

growth and development of crops. In this review we will first focus on the effects that CDs have on the growth of plants in agriculture. Next, we will summarize the underlying mechanism of CDs in promoting or inhibiting plant growth. Following that, the functions of CDs in the resistance of plants against abiotic/ biotic stresses will be surveyed (Fig. 1). Lastly, some perspectives regarding the challenges and opportunities for CD studies will be discussed. Generally, CDs mainly include graphene quantum dots (GQDs), carbon nanodots (CNDs) and polymer dots (PDs), ${ }^{32}$ all of them are consistently referred to as CDs in this review.

\section{Uptake, translocation and accumulation of CDs in plants}

The stable and unique fluorescence signal of CDs provides a promising approach by which to trace them in plants. Several studies have revealed the uptake of CDs by plants through fluorescence imaging, transmission electron microscopy (TEM) observations or Raman spectroscopic measurements. ${ }^{26,28,33-36}$ For example, Loukanov et al. used tobacco bright yellow-2 (BY-2) plant cells to investigate the real time monitoring and quantification of $\mathrm{CD}$ uptake by fluorescence and confocal microscopy. ${ }^{37}$ In our previous study, the mung bean was adopted as a model plant to investigate the uptake, and translocation of CDs in plants. ${ }^{33}$ Hydroponics guarantee that the CDs are readily available for adsorption and uptake by the roots of the mung bean plants. After 5 days of cultivation at $25{ }^{\circ} \mathrm{C}$, the germination of the seeds and growth of the mung bean seedlings were promoted. The clear concentration-dependent reddish-orange fluorescence under $365 \mathrm{~nm}$ UV light provided evidence for the increased absorption of CDs by the mung bean plant (Fig. 2A). A confocal laser scanning microscope was employed to image the root, stem, cotyledon and leaves to locate the CDs in the mung bean seedlings after 5 days of incubation. As can be seen from the cross and longitudinal sections of the mung bean sprouts in Fig. $2 \mathrm{~B}$ and $\mathrm{C}$, the fluorescence signals of the CDs were found to be mainly located in the vascular system in the parts of the root, stem and leaves. TEM images of the cross sections of mung bean seedlings from the control and $\mathrm{CD}$ treatments showed the presence of CDs that were agglomerated and formed relatively larger clusters in the intercellular space (Fig. 2D). It can be concluded that the CDs penetrate the seed coating via the intercellular space and accumulate in the cotyledons to accelerate seed germination. After the root emerged, the CDs were adsorbed on the root surface and penetrated into the root vascular bundles. Then, the CDs were transferred from the roots to the stems and leaves through the vascular system and were found to be finally located in the veins of the leaves rather than the mesophyll system (Fig. 2E). A similar upward transport of CDs from the root of mung beans to the stem and leaves was reported by Kang et $a l^{26,36} \mathrm{It}$ should be noted that the distribution pattern of CDs in plants depends on their surface modification. ${ }^{38}$

\section{Effects of CDs on plant growth and development}

Crop plants play a key role in maintaining ecological balance and as food for human survival and feedstocks for industrial 

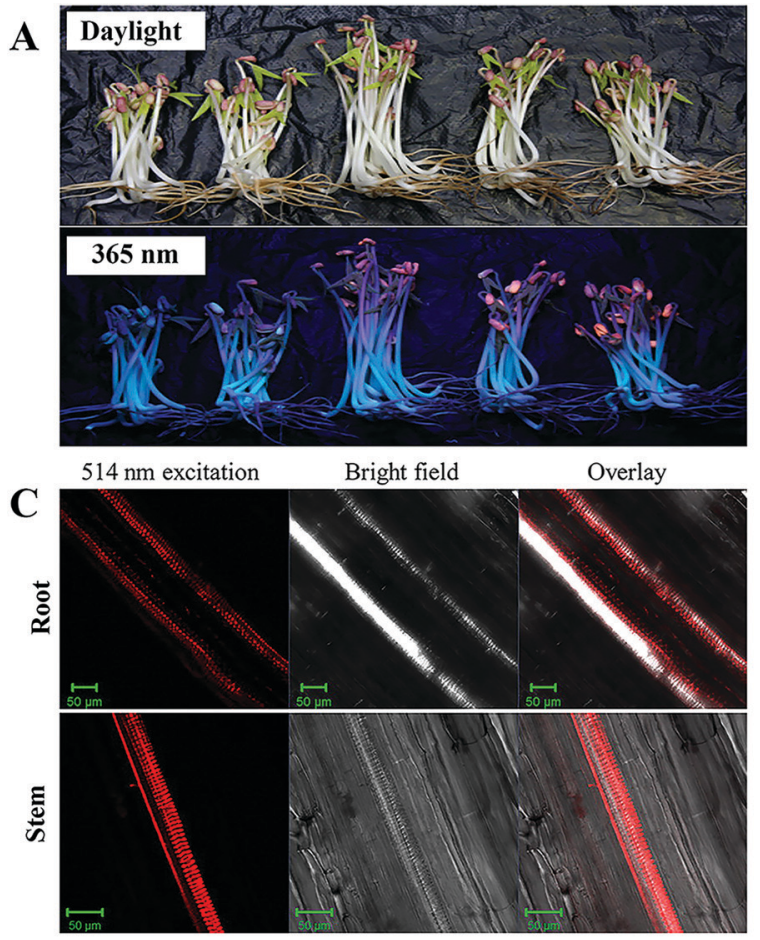

D

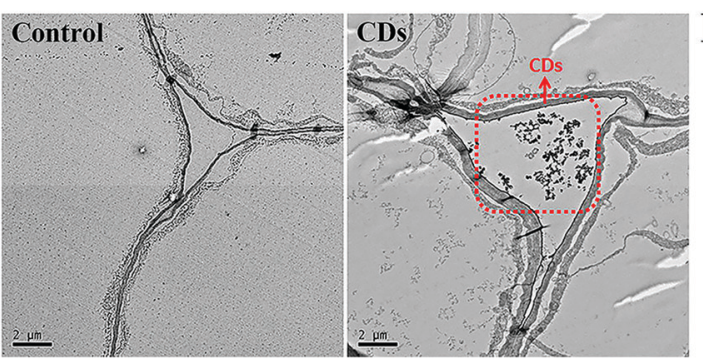

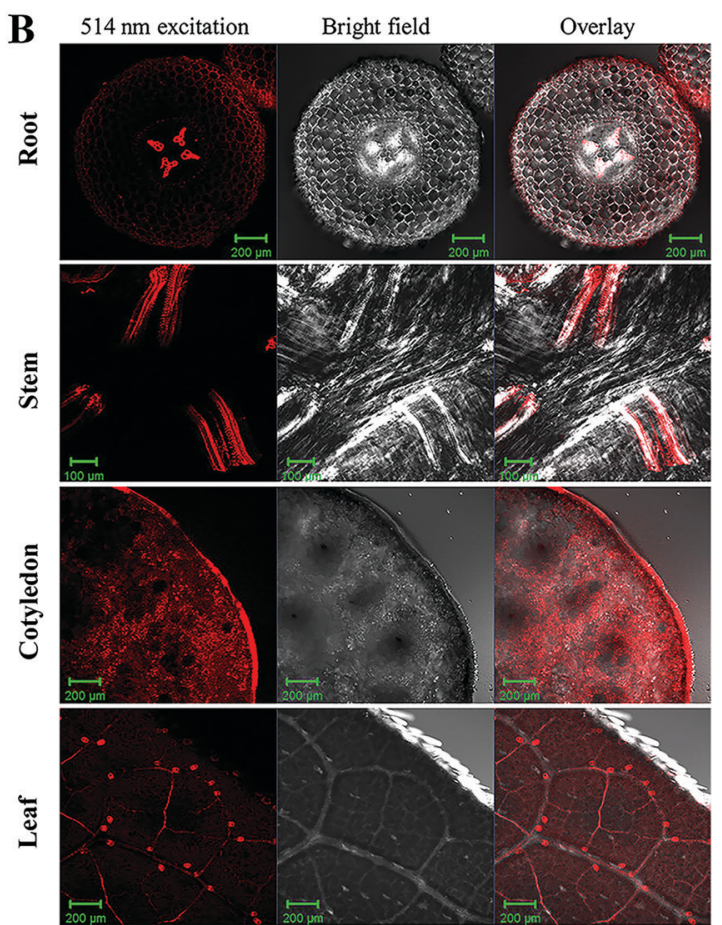

$\mathbf{E}$
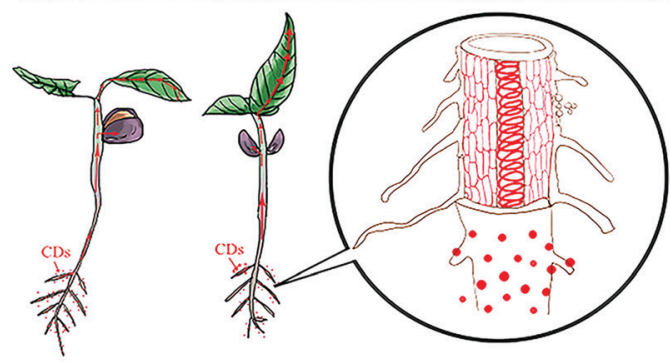

Fig. 2 Uptake and translocation of CDs in mung bean plants. (A) Digital photos of mung bean sprouts under daylight and $365 \mathrm{~nm}$ UV light; LSM images of transverse sections from root, stem, cotyledon, leaf (B) and longitudinal sections from root, stem (C) of mung beans cultured with $\mathrm{CDs}\left(1.0 \mathrm{mg} \mathrm{mL}^{-1}\right.$ ) for $5 \mathrm{~d}$; (D) TEM image of mung bean roots cultured with pure water and CDs (1.0 mg mL $\left.{ }^{-1}\right)$ after $5 \mathrm{~d}$; (E) schematic illustration of uptake, transport, and accumulation of CDs by a mung bean plant. ${ }^{33}$ Adapted with permission from the American Chemical Society, Copyright 2016 (ref. 33 ).

production, which are facing the challenge of an increase in production in the wake of the increasing world population. ${ }^{5}$ Qu et al. first reported the biocompatibility of CDs using the bean sprout as a model. ${ }^{25}$ In their study, CDs prepared from citric acid and urea showed nontoxicity to the bean sprout plant, which were used as a new type of biocompatible fluorescent ink. Subsequently, Ma et al. conducted parallel comparative studies on the toxic effects of unmodified CdTe quantum dots, gold nanoparticles, and carbon nanodots on live cells as well as green gram sprouts. ${ }^{39}$ The CDs were found to exert no obvious toxicity on both live cells and the growth of green gram sprouts, showing the best biocompatibility compared to CdTe quantum dots and gold nanoparticles. And then, the potential effect of CDs on the growth of various crop plants was sequentially reported.

\subsection{Enhancement effect}

Mung bean is the most commonly used plant model in studies due to its fast growing rate. ${ }^{18,26,33,36,40}$ Among these studies, CDs played a role in the elongation of root and stem, biomass accumulation, and enhanced the carbohydrates content and photosynthesis (mentioned below) of the mung bean sprouts. For example, Kang et al. exposed mung bean sprouts to CDs, in which CDs at $0.02 \mathrm{mg} \mathrm{mL}^{-1}$ were found to improve the root length, stem length, root vigor and single plant fresh weight by $29.9 \%, 18.3 \%, 36.1 \%$ and $14.9 \%$, respectively (Fig. $3 \mathrm{~A}$ ). ${ }^{26}$ Similar results were obtained with CDs prepared from $p$-phenylenediamine in our previous study, where the optimal concentration of CDs was $0.4 \mathrm{mg} \mathrm{mL}{ }^{-1} \cdot{ }^{18}$ Simultaneously, Kang's group further prepared a chiral CD sample via a onepot hydrothermal method from chiral molecules of cysteine and citric acid. These chiral CDs were further used to investigate the systemic effects on the growth of the mung bean plant. The results indicated that the D-CDs showed better enhancement effect on the growth of the mung bean plant than L-CDs, especially in the root vigor and the activity of the Rubisco enzyme, and carbohydrate accumulation. ${ }^{36}$ Furthermore, Li et al. prepared nitrogen-rich (20\%) CDs using a solid-state method from citric acid and thiourea, which were applied as a nanofertilizer. ${ }^{40}$ They found 
A

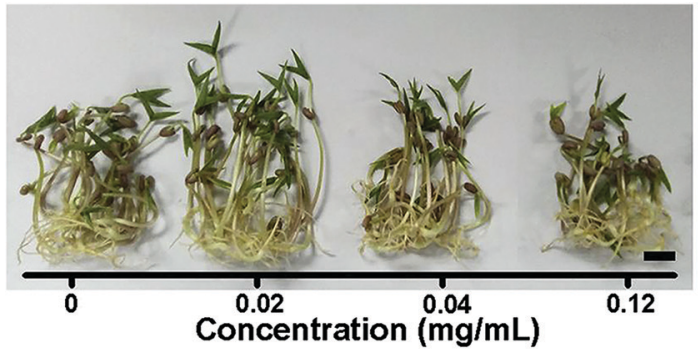

With CDs
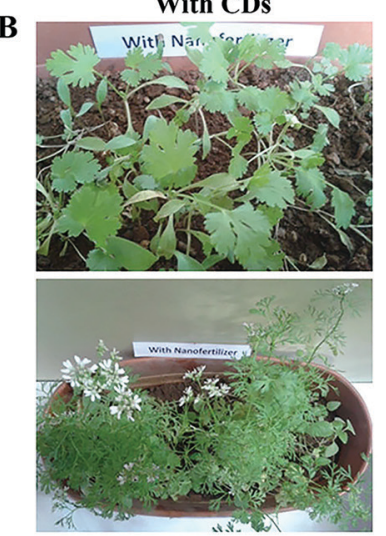

C With Nanofertilizer

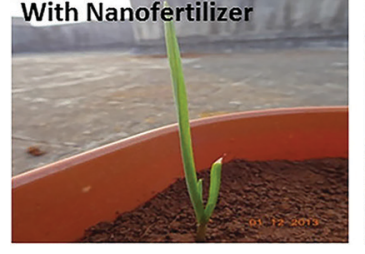

D
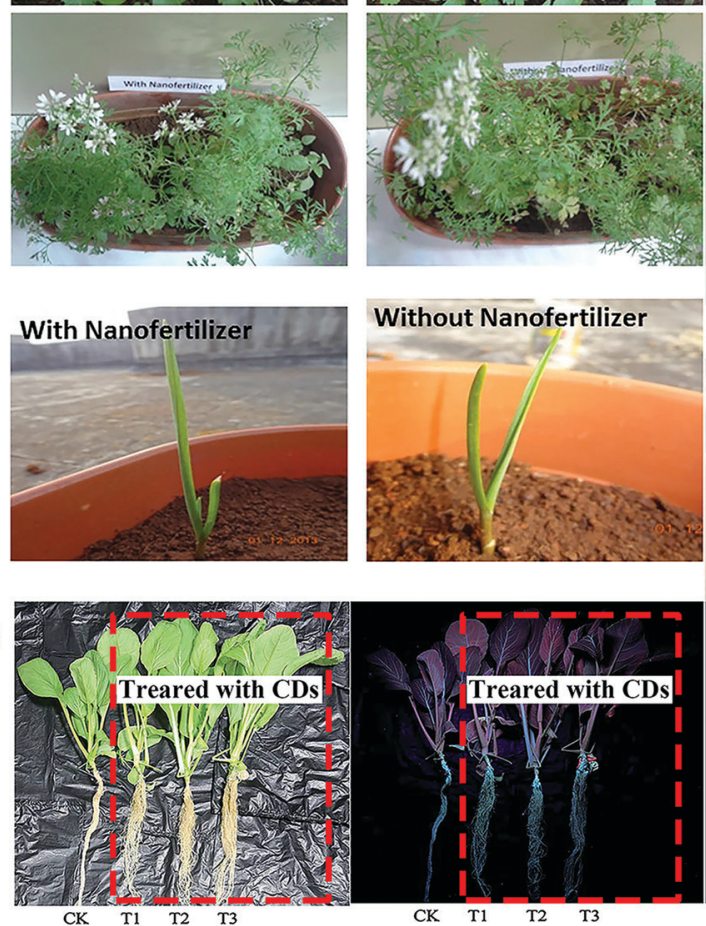

Without Nanofertilizer

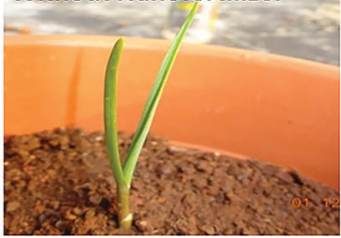

$\mathbf{E}$
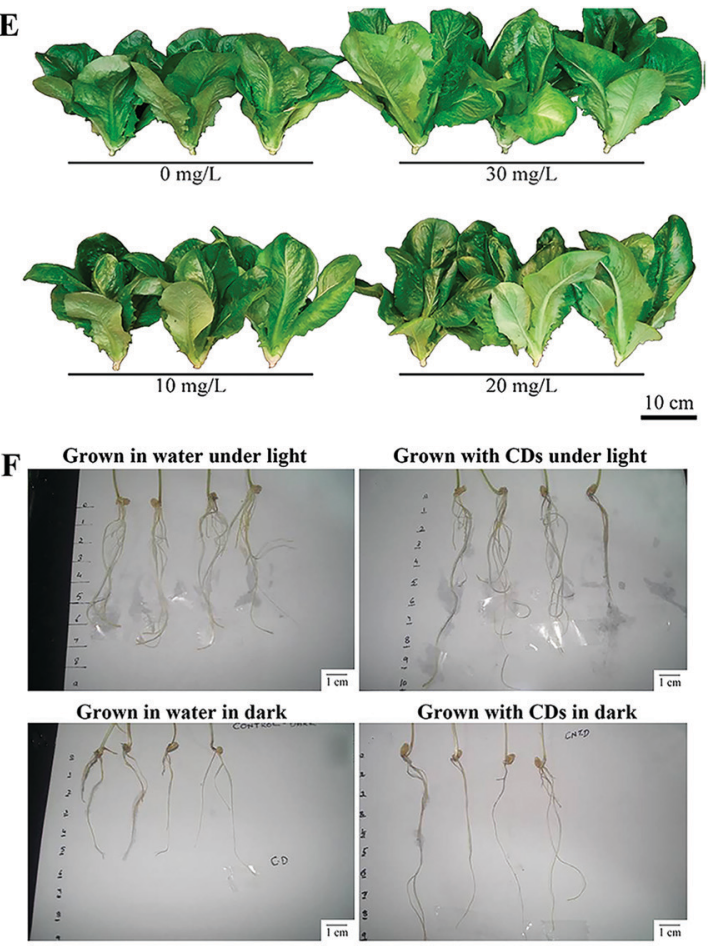

Grown with CDs in dark

G

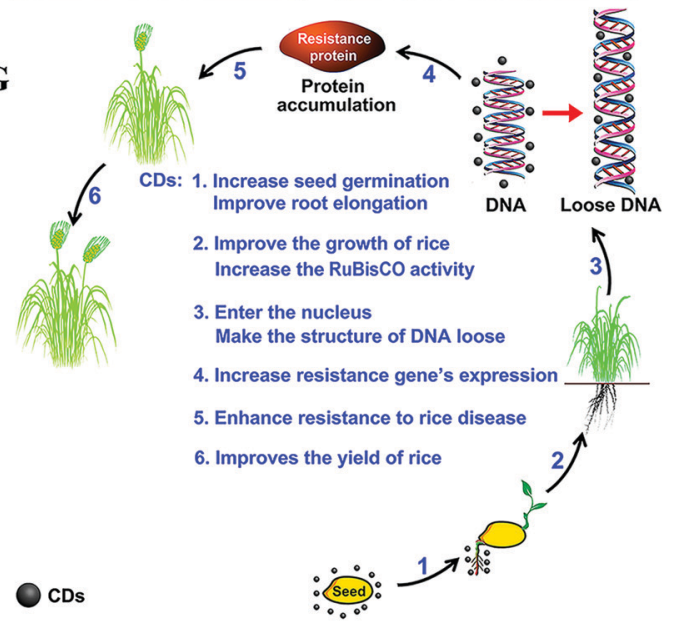

Fig. 3 Enhancement effect of CDs on the growth of (A) mung bean, ${ }^{26}$ (B) coriander, (C) garlic, ${ }^{41}$ (D) Brassica parachinensis L., ${ }^{43}$ (E) romaine lettuce, ${ }^{44}$ (F) wheat ${ }^{35}$ and (G) rice plants. ${ }^{28}$ Reprinted with permission from Elsevier, Copyright 2018 (ref. 26); the Society of Chemical Industry, Copyright 2015 ; the Royal Society of Chemistry, Copyright 2017 (ref. 43 and 69); the American Chemical Society, Copyright 2017 (ref. 44 and 28); the Author (ref. 35).

that $17.45 \%$ more bean sprouts were yielded by the same amount of mung bean seeds when cultured in an aqueous solution $\left(0.2 \mathrm{mg} \mathrm{mL} \mathrm{m}^{-1}\right)$ of the CDs than in the pure water control. The fertilizing effects of the CDs were much more efficient than those of urea, which has a much higher $\mathrm{N}$ content (46\%). They determined that the fabricated N-CDs demonstrate great potential as a luminescent nanofertilizer.

Besides the mung bean, various other species of crop plants have been employed to investigate the potential effect of CDs on their growth. Late et al. fabricated graphene quantum dots (GQDs) from graphite powder as a plant growth regulator, which enhanced the growth rate of coriander and garlic plants, including leaves, roots, shoots, flowers and fruits (Fig. $3 \mathrm{~B}$ and C). ${ }^{41}$ Tripathi et al. compared the influence of the morphology of carbon nanostructures on the stimulated growth of a gram plant. In their study, the CDs showed significant enhancement of the growth of the gram plant, although to a lesser extent than the performance of single-walled carbon nanotubes and carbon nanowhiskers. ${ }^{42}$ In our previous studies, CDs that were prepared from pollen exhibited significant promoting effects on the growth of Brassica parachinensis L. and Romaine lettuce (Lactuca sativa) (Fig. 3D and E). ${ }^{43,44}$ Furthermore, the enhancement effects of CDs on the two main grain crops of wheat and rice were reported. ${ }^{28,35}$ In a seed germination experiment on wheat, CDs were found to enhance the growth of the roots more than the shoot both under light and dark conditions (Fig. 3F). ${ }^{25}$ Kang's group conducted a 
systematic investigation on how CDs affect the growth of rice plants over a whole growth season. ${ }^{26}$ They found that CDs $\left(0.56 \mathrm{mg} \mathrm{mL}^{-1}\right)$ were capable of entering the cells of the plants, reaching the nuclei and then promoting plant growth, through the expression of disease-resistant genes, leading to a $14.8 \%$ enhancement in the total rice yield (mentioned in detail below) (Fig. 3G). Simultaneously, the same CDs significantly improved the yield of 8 different dicotyledons (soybean, tomato, eggplant, capsicum, watermelon, radish, celery and cabbage) by $20 \%$ in another of their studies. ${ }^{45}$

\subsection{Inhibition effect}

Despite the promoting functions of CDs on the growths of various crop plants mentioned above, inhibition of the growth of crops was also observed. After exposure to maize plants in a sand matrix for 4 weeks, CDs at 1000 and $2000 \mathrm{mg} \mathrm{L}^{-1}$ significantly reduced the fresh weights of the roots $(57 \%$ and $68 \%$ ) and shoots (38\% and $72 \%$ ) of the plants (Fig. $4 \mathrm{~A}$ ). ${ }^{34}$ Meanwhile, CDs at such high concentrations caused oxidative damage (higher $\mathrm{H}_{2} \mathrm{O}_{2}$ content and lipid peroxidation) in the maize plants. In response, the antioxidant defense systems (catalase, ascorbate peroxidase, guaiacol peroxidase and superoxide dismutase) of the maize plants were enhanced to alleviate the CD-mediated oxidant damage. Similarly, Wang et al. integrated transcriptomic, physiological and metabolomic techniques to systematically investigate the fate and phytotoxicity of CDs using Arabidopsis thaliana (L.) as a plant model. ${ }^{46}$ CDs at over $125 \mathrm{mg} \mathrm{L}^{-1}$ significantly reduced the root elongation of Arabidopsis thaliana (L.) compared with that of the control groups, while $62.5 \mathrm{mg} \mathrm{\textrm {L } ^ { - 1 }}$ of CDs had no influence (Fig. 4B). In further RNA-seq analyses of the treated Arabidopsis thaliana (L.) with CDs at $1000 \mathrm{mg} \mathrm{L}^{-1}, 715$ and 636 genes in roots and shoots were up-regulated, which were involved in stimulus response, UDP-glycosyltransferase activity and cellular response to phosphate starvation. Meanwhile, 552 and 707 down-regulated genes in roots and shoots, respectively, were mainly involved in chloroplast structure and function. Similarly, the physiological results indicated that the antioxidant response (activities of glutathione reductase) of Arabidopsis thaliana (L.) was activated and the photosynthesis enzymes (Rubisco, FBP and FDA) were reduced.

Summarized from the studies mentioned above, the potential effects of CDs on the growth of crop plants were found to be concentration-dependent, i.e., CDs at a relatively lower dose contribute to crop growth, while a higher dose inhibits it. Generally, several internal and external factors are responsible for the growth of the plant. These internal factors include photosynthesis, nutrient assimilation and plant resistance, ${ }^{4-50}$ and the external factors involve biological nitrogen fixation, ${ }^{51}$ pest infection, environmental stress injury, etc. Therefore, in the following section, we will focus on the interaction between CDs and these physiological processes in plants, as well as the external factors involved in plant growth.

\section{Effects of CDs on photosynthesis in plants}

Photosynthesis plays a key role in plant growth and biomass accumulation. As is well known, two energy conversion processes are involved in the photosynthesis of plants, including conversion from optical to electric energy and then to chemical energy. Chromophores such as chlorophylls and xanthophylls on the thylakoid membrane of the chloroplasts act as antennae to harvest light during photosynthesis. ${ }^{52}$ Then, the energy absorbed by the chromophores is transported to photosystems I and II through a series of electron transfer chains, accompanied by the production of oxygen and adenosine triphosphate (ATP) as a result of water spitting and the reduction of nicotinamide adenine dinucleotide phosphate (NADP) to NADPH. ${ }^{53}$ Finally, the ATP and NADPH are involved in $\mathrm{CO}_{2}$ assimilation, in which $\mathrm{CO}_{2}$ is fixed and transformed to carbohydrate, catalyzed by photosynthetic enzymes. ${ }^{53}$ Therefore, the intermediate process of electron transfer and the immobilization of $\mathrm{CO}_{2}$ play key roles in the rate of photosynthesis.

CDs, as a good electron donor as well as acceptor, ${ }^{5,55}$ have been employed in light energy conversion applications. ${ }^{56,57}$
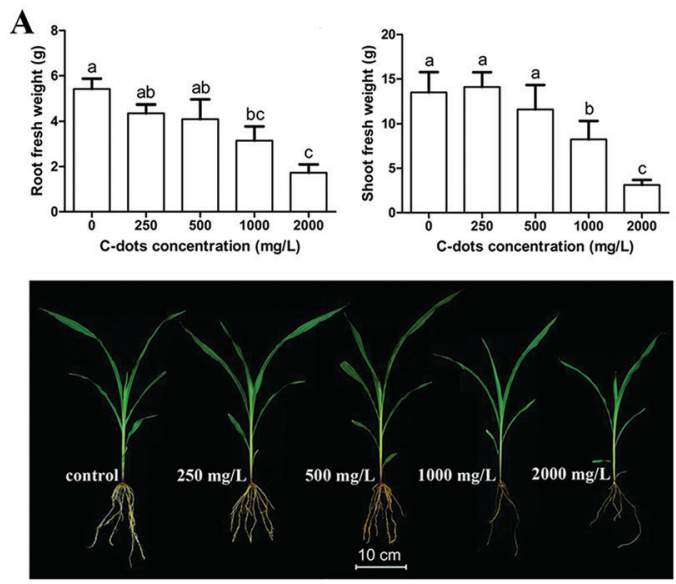

B
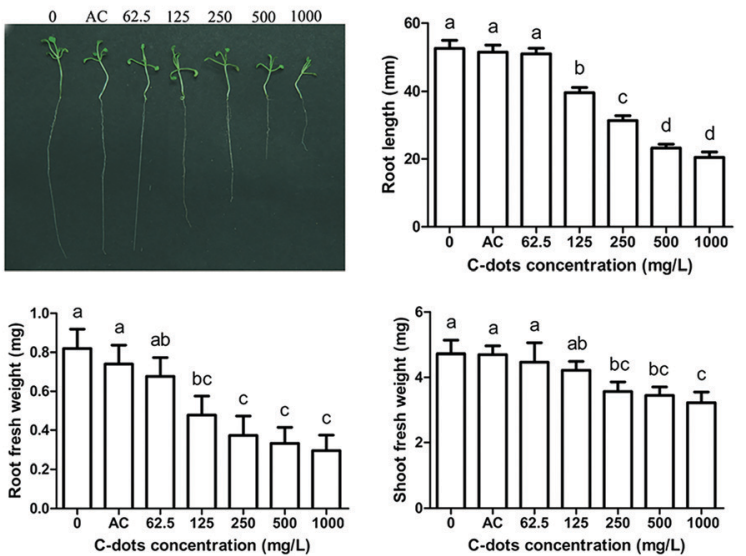

Fig. 4 Inhibition of CDs on the growth of (A) maize ${ }^{34}$ and (B) Arabidopsis thaliana (L.). ${ }^{46}$ Reprinted with permission from Taylor \& Francis, Copyright 2016 (ref. 34); the Royal Society of Chemistry, Copyright 2018 (ref. 46). 

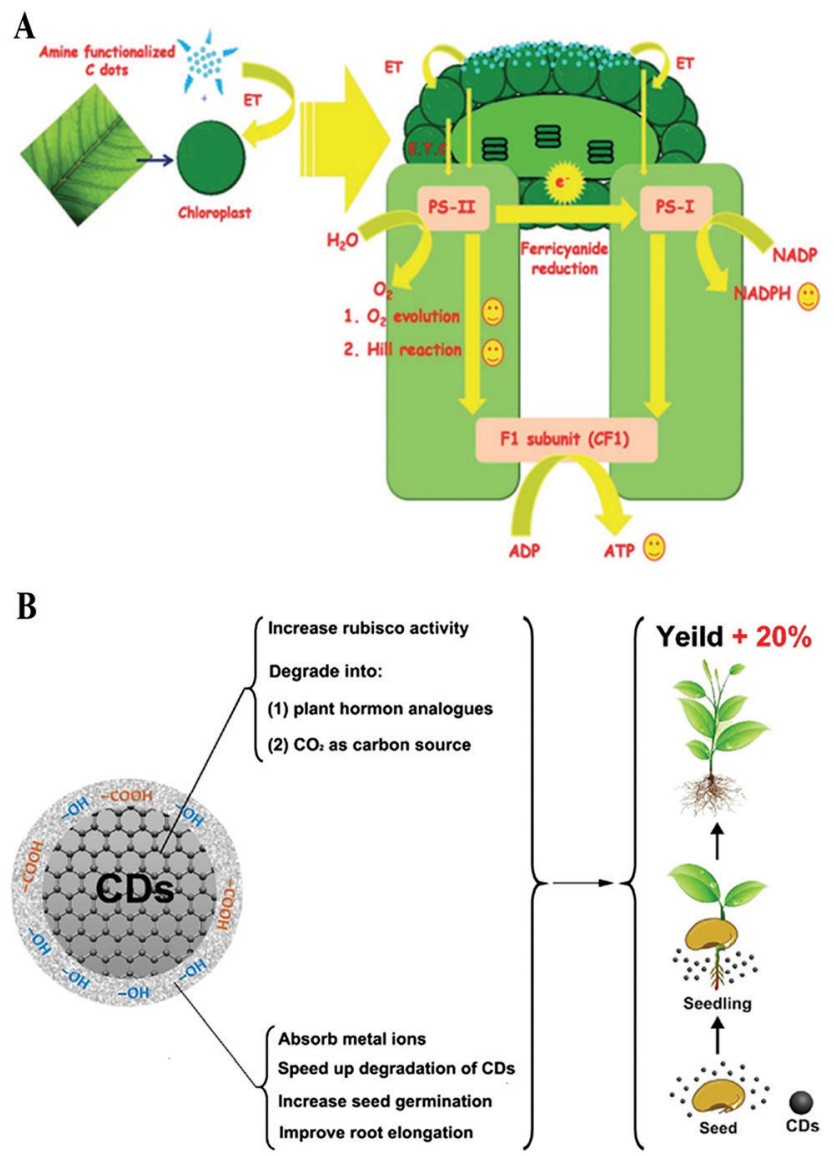

Fig. 5 Schematic representation illustrating the function of CDs in the (A) electron transfer PS $\|^{60}$ and (B) nutrition assimilation. ${ }^{45}$ Reprinted with permission from the Royal Society of Chemistry, Copyright 2014 (ref. 60); Tsinghua University Press and Springer-Verlag GmbH Germany, part of Springer Nature, Copyright 2019 (ref. 45).

The doping modification of CDs can increase the transfer of charges to form more electronic holes under light irradiation, which increases the photoelectric conversion efficiency. ${ }^{58,59}$ Chandra et al. first proposed CD-based light stimulated electron transfer processes in photosynthetic system/light harvesting complexes (Fig. 5A). ${ }^{60}$ In their study, the amine functionalized CDs were found to strongly conjugate over the surface of the chloroplast and transfer electrons towards the chloroplast via the assistance of absorbed light or photons, which directly accelerates the whole chain electron transfer pathway in the light reaction of photosynthesis. As a result, photosynthesis is promoted by CDs. Subsequently, this property of CDs of accelerating the transfer of electrons was further demonstrated in further studies. ${ }^{26,61}$

Besides the light reaction of photosynthesis, $\mathrm{CO}_{2}$ assimilation is mainly responsible for the conversion of electrical energy to chemical energy in photosynthesis. Ribulose bisphosphate carboxylase oxygenase (Rubisco) is a key enzyme in the Calvin cycle that fixes $\mathrm{CO}_{2}$ in photosynthesis. ${ }^{53}$ The activity of Rubisco directly affects the photosynthetic rate and the accumulation of carbohydrates. Kang et al. first determined the enhancing effect of CDs on Rubisco activity using mung bean as a model. ${ }^{26}$
They found that CD-treated mung bean seedlings showed 30.9\% higher Rubisco activity than those in the control group. Subsequently, they reported a similar enhancing effect of CDs on the Rubisco activity of rice, Trifolium repens L. and Arabidopsis thaliana plants. ${ }^{28,45}$ Additionally, the CDs were degraded by horseradish peroxidase (HRP) and $\mathrm{H}_{2} \mathrm{O}_{2}$ in plants to form plant-hormone analogues and $\mathrm{CO}_{2}$. And then, the hormone analogues promoted plant growth, while the $\mathrm{CO}_{2}$ was converted into carbohydrates through the Calvin cycle in photosynthesis (Fig. 5B). Finally, the CD-treated plants showed a 14.8-20\% increase in yield. $^{28,45}$ This result was consistent with the degradation of graphene to $\mathrm{CO}_{2}$ in rice plants reported by Huang et al. using ${ }^{14} \mathrm{C}$-labeled graphene. ${ }^{62}$ The same enhancing effect of CDs on photosynthesis was also demonstrated in Chlorella vulgaris. ${ }^{63}$ Furthermore, the fluorescence of CDs means that they can serve as a UV-to-blue light conversion material in a plant to accelerate its rate of photosynthesis. ${ }^{64}$

\section{Effects of CDs on nutrition assimilation by plants}

Besides photosynthesis, nutrition assimilation is another key factor that affects plant growth. The hydrophilic groups (hydroxyl and carboxyl groups) on the surface of CDs provide abundant binding sites for water molecules, which enter the plant along with the CDs. Finally, adequate moisture in plant seeds can promote their germination and accelerate the growth of plant seedlings. ${ }^{28,45}$ In a seed germination test, CD-treated mung bean seeds showed $34.9 \%$ higher moisture levels than those in the control group, indicating that CDs can promote the water uptake capacity of seeds. ${ }^{26}$ Water uptake by plants is accompanied by the uptake of nutrition. The hydroxyl and carboxyl groups on their surface endows CDs with adsorbent capability for various metal ions $\left(\mathrm{K}^{+}, \mathrm{Ca}^{2+}, \mathrm{Mg}^{2+}, \mathrm{Cu}^{2+}, \mathrm{Zn}^{2+}\right.$, $\mathrm{Mn}^{2+}$ and $\mathrm{Fe}^{3+}$ ), which are important nutrients for plant growth. The higher metal nutrient content in CD-treated plants than in the controls indicates that CDs are able to deliver them into plants (Fig. 5B). ${ }^{45}$

\section{Effects of CDs on the resistance of plants toward abiotic/biotic stress}

\subsection{Abiotic stress}

According to a report by the Food and Agriculture Organization of the United Nations (FAO) in 2007, more than 96\% of global rural land area is affected by various abiotic stresses (drought, cold, salt, strong solar radiation, abuse of pesticides, etc.) that annually lead to about half of the crop yield lost worldwide. ${ }^{65}$ Elevation in the generation of reactive oxygen species (ROS) is the main pathway for abiotic stresses that affect plant growth. Accumulation of ROS in cells usually leads to oxidative damage to proteins, lipids, carbohydrates and DNA. ${ }^{66,67}$ In recent years, CDs with radical scavenging properties due to the electron donor and acceptor carboxyl and amino groups on their surface have been reported. ${ }^{68,69}$ Through a hydrogen atom transfer 
A
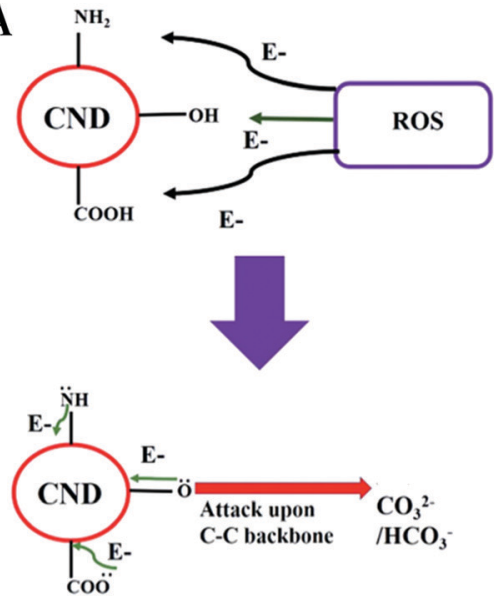

B

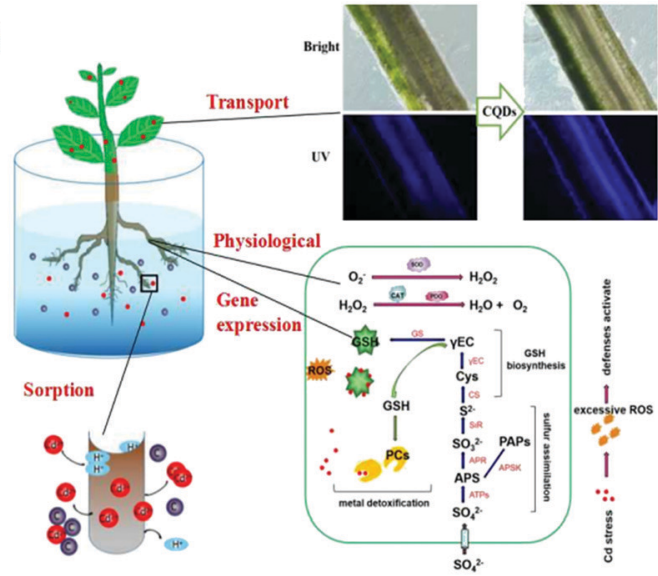

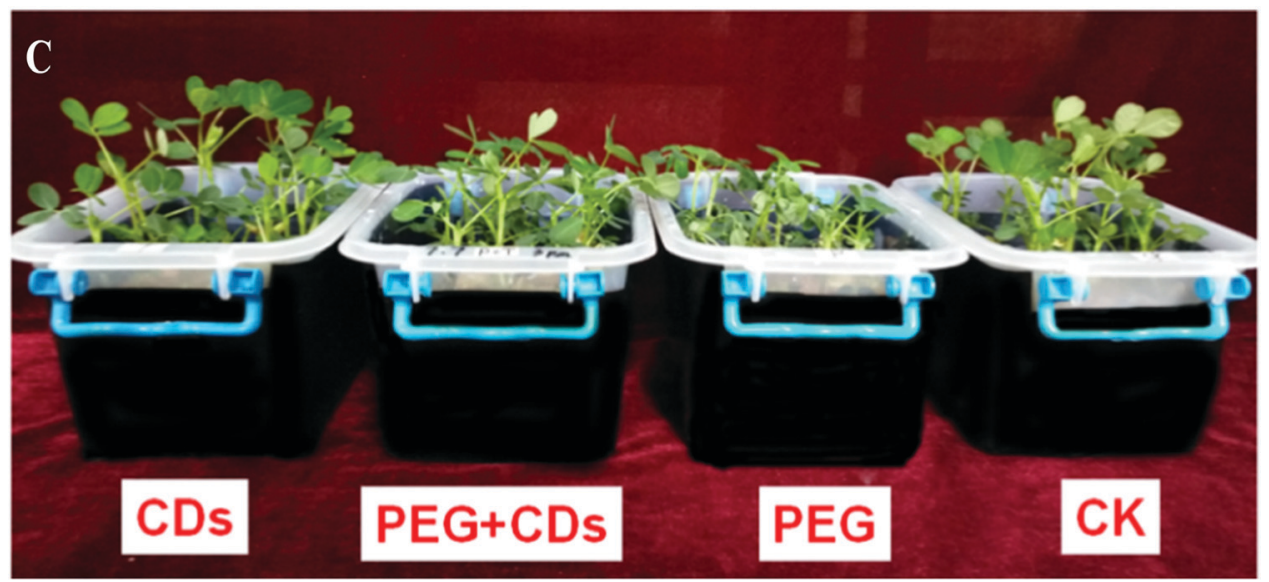

Fig. 6 (A) Mechanism for ROS scavenging ${ }^{69}$ and (B) alleviating abiotic stress ${ }^{74}$ of CDs; (C) anti-drought effect of CDs on peanut seedlings. ${ }^{27}$ Reprinted with permission from the Royal Society of Chemistry, Copyright 2014 (ref. 69); Elsevier, Copyright 2019 (ref. 74); the American Chemical Society, Copyright 2018 (ref. 27).

mechanism, $\mathrm{DPPH}^{\bullet}$ radicals can be converted to stable DPPH-H by CDs (Fig. 6A). Additionally, Su et al. studied the effects of CDs on peanut growth under PEG simulated drought conditions. ${ }^{27}$ It was found that drought severely inhibits the growth of peanuts, which was relieved by the CDs. The antioxidant enzyme activities in the CD-treated peanuts were further investigated and the results showed that CDs increased the activities of superoxide dismutase (SOD), peroxidase (POD) and catalase (CAT) in peanuts and reduced their malondialdehyde (MDA) content. Therefore, they concluded that CDs increased the stress resistance of peanuts, thereby alleviating the drought stress they experienced (Fig. 6C). ${ }^{27}$ With the combination of radical scavenging properties and the promotion of antioxidant enzyme activities, CDs can protect plants from abiotic stress (Fig. 6B). ${ }^{38,70-72}$ This function of CDs was further demonstrated using Chlorella vulgaris, in which CDs acting as an antioxidant can protect the plants against UV radiation damage and enhance their growth rate and biomass. ${ }^{63}$ Furthermore, Li et al treated wheat and citrus seedlings with CDs under their exposure to heavy metal $\mathrm{Cd}^{2+}$ ions. It was found that CDs can bind with freely dissolved $\mathrm{Cd}^{2+}$ ions and then inhibit their absorption into the plants. Meanwhile, CDs prevented the $\mathrm{Cd}^{2+}$-mediated inhibition of plant growth by reinstating the anthocyanin content, promoting the activity of the antioxidant enzymes and alleviating cell membrane peroxidation damage (Fig. 6B). ${ }^{73,74}$ Therefore, CDs can alleviate abiotic stress in plants, which lays the foundation for their application in environmental protection and agricultural production.

\subsection{Biotic stress}

Infection with phytopathogens is a typical biotic stress, which annually leads to severe reduction in crop production. In an in vivo inoculation of sheath blight, CD pre-cultured rice leaves showed high resistance to infection with the disease, since the length of the scabs on the leaves decreased by about $60 \%$ in comparison to that in the control, in seedlings aged 60 to 120 days (Fig. 7A). ${ }^{28}$ A series of experimental results confirmed that CDs enter the nucleus and bond to DNA. Among the expressions of genes up-regulated by CDs, three genes were found to be related to plant-pathogen interactions, which may strongly account for the plant disease resistance though only one gene, Os06g32600 (predicted as the thionin gene), confirmed by real-time polymerase chain reaction (PCR) (Fig. 7B-D). All of 
A
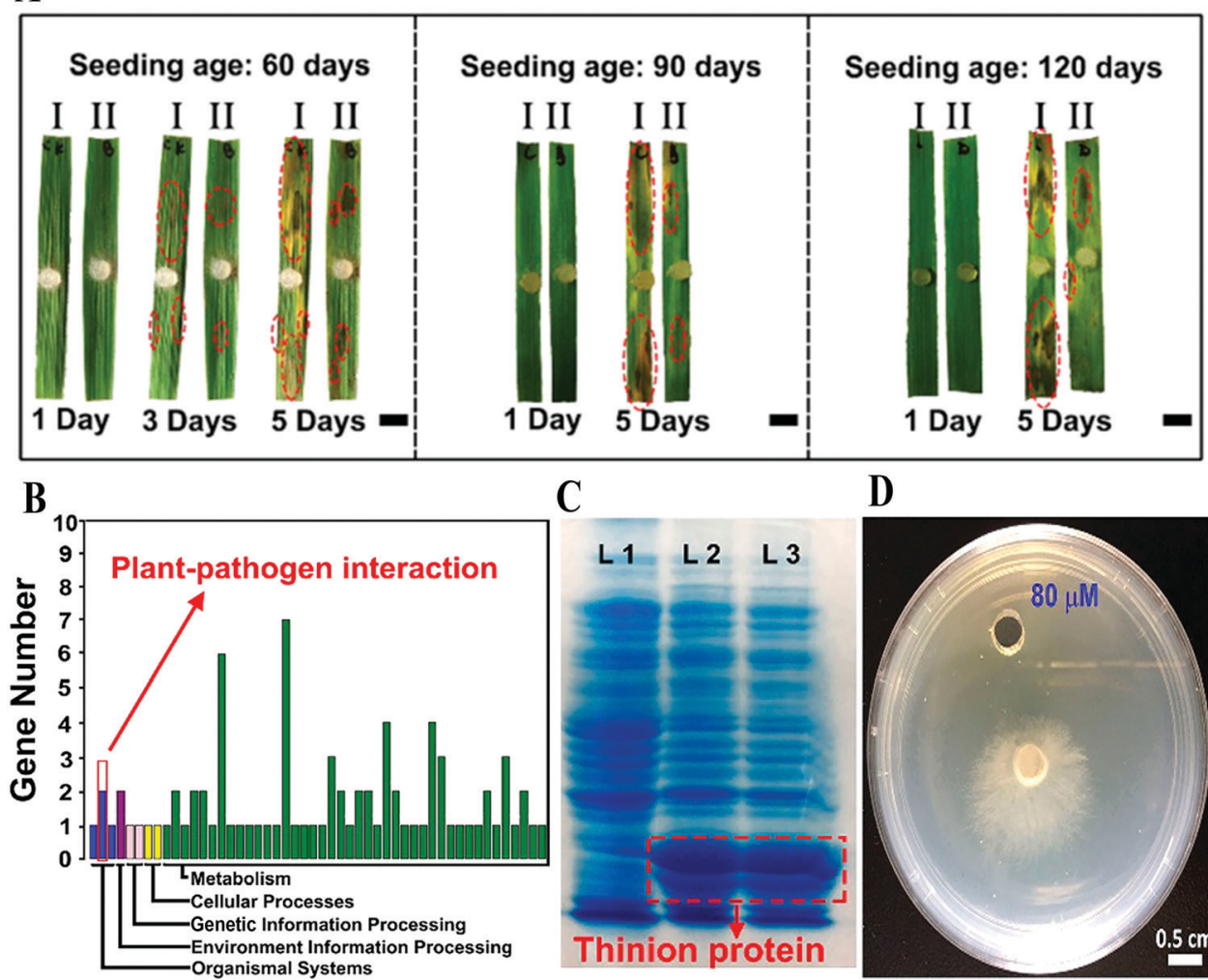

C

D

Fig. 7 (A) Digital photographs of sheath blight-infected rice leaves with and without CDs in different aged seedlings; (B) expression of plant-pathogen interaction genes of Os06g32600; (C) the image of nondenaturing gel electrophoresis (red traces: expression of GST-fused thinion protein). (D) The effect of Rhizoctonia solani growth on $80 \mu \mathrm{M}$ pure thionin-like protein. ${ }^{28}$ Reprinted with permission from the American Chemical Society, Copyright 2018 (ref. 28).

these results suggest that $\mathrm{CD}$ treatment may have an important function in enhancing the disease resistance of crops through inducing the over-expression of related genes.

\section{Effects of CDs on nitrogen fixation by azotobacter chroococcum}

Nitrogen is the most important nutrient for plant growth and the soil loses a lot of nitrogen every year. ${ }^{75}$ The atmosphere contains an abundance of nitrogen gas $\left(\mathrm{N}_{2}\right)$, which is not directly available to plants. Interestingly, specific nitrogen-fixing bacteria are able to convert $\mathrm{N}_{2}$ to ammonia $\left(\mathrm{NH}_{3}\right)$ in the presence of nitrogenase, which is then available for the plant to absorb. Nitrogen fixation by nitrogen-fixing bacteria is a key stage in the nitrogen cycle. ${ }^{76,77}$ Kang et al. conducted an investigation to study the impact of CDs on biological nitrogen fixation using azotobacter chroococcum as a model nitrogenfixing bacterium. ${ }^{29}$ In azotobacter chroococcum, they found that CDs can improve the activity of nitrogenase by affecting the secondary structure of nitrogenase and improving the electron transfer in the biocatalytic process (Fig. 8). Finally, the activity of azotobacter treated with $4 \mu \mathrm{g} \mathrm{mL} \mathrm{m}^{-1}$ of CDs was increased by $158 \%$ compared to that of the control group. CDs provide an economical and environmentally friendly approach to

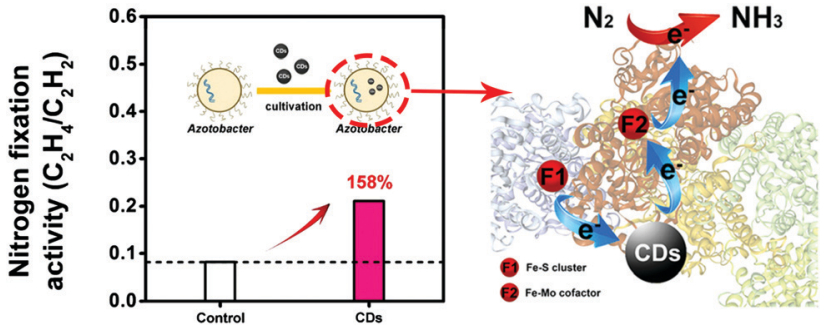

Fig. 8 Schematic representation illustrating the function of CDs in the nitrogen fixation of azotobacter chroococcum. ${ }^{29}$ Adapted with permission from the American Chemical Society, Copyright 2018 (ref. 29).

improving biological nitrogen fixation by nitrogen-fixing bacteria when there is insufficient nitrogen fertilizer available in agriculture.

\section{Antibacterial activity of CDs}

In order to control the infection of phytopathogens into crops, bactericides/fungicides have been widely applied in agriculture. Ubiquitous and inefficient use of pesticides severely threatens biodiversity and ecosystem functions. ${ }^{3,4}$ Up to now, various nanomaterials have been applied in the control of plant disease. ${ }^{12,78}$ Although there is no related application of CDs in agriculture for the control of crop diseases, the broad-spectrum antibacterial/antifungal 


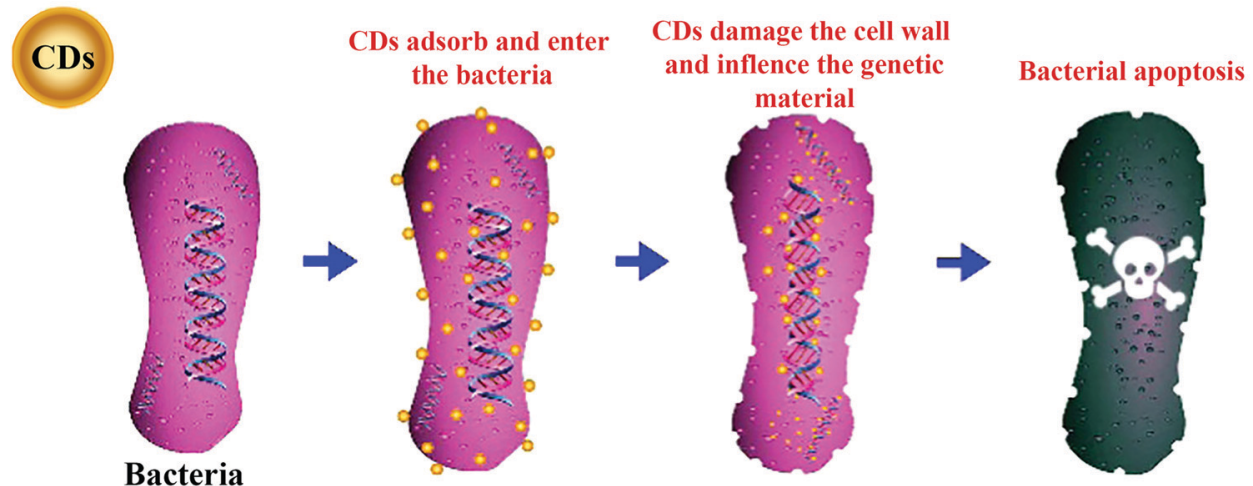

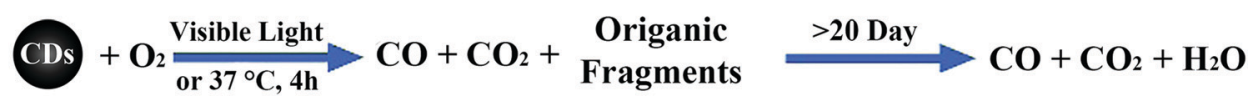

Fig. 9 Antibacterial mechanism of CDs. ${ }^{80}$ Reprinted with permission from the American Chemical Society, Copyright 2018 (ref. 80 ).

activity of CDs has been reported, which lays the foundation for their application in the control and management of crop diseases. Yang et al. prepared CDs using metronidazole (a selective anaerobic microbicide), which exhibited selective antibacterial activity against obligate anaerobic microorganisms for the first time. ${ }^{79}$ Subsequently, Kang's group fabricated lowtoxic and degradable CDs from vitamin $\mathrm{C}$ and demonstrated their broad-spectrum antibacterial/antifungal activity against Gram-positive ( $S$. aureus and B. subtilis) and Gram-negative (Bacillus sp. WL-6 and E. coli) bacteria, as well as a pathogenic fungus ( $R$. solani and $P$. grisea) ${ }^{80}$ Their antibacterial and antifungal mechanisms indicate that CDs can destroy bacterial walls and the secondary structures of DNA/RNA in bacteria and fungi, and finally kill them (Fig. 9). These CDs were then used as a secure and economical additive to prepare protective coatings with robust antibiofilm and anticorrosion properties. ${ }^{81}$ Although these studies have laid the foundation for the applications in the control and management of crop diseases, further investigations are required on the feasibility of the antibacterial/antifungal activity of CDs prepared from different precursors as well as on phytopathogens.

\section{Summary and outlook}

Applications of CDs on crops have been an emerging theme in recent years. In this article, we reviewed the recent developments made towards the applications of CDs in agriculture, focusing on the interactions between crops and CDs in great detail. The CDs in most of the studies showed a positive effect on crop plants, including their growth and resistance against abiotic and biotic stresses, unless they were applied at higher concentrations. CDs at an optimal dose can promote the growth of crop plants through accelerating the photosynthesis and nutrition assimilation in plants as well as the nitrogen fixation of azotobacter. Due to their intrinsic free radical scavenging properties and influence on the antioxidant defense system and expression of diseaseresistance genes, CDs can enhance the resistance of crops to abiotic/biotic stresses. Besides this, CDs show broad-spectrum antibacterial activity against bacteria and fungi.

Although important progress has been achieved in this field with CDs, more efforts are still required for the applications of CDs in agriculture. (1) As demonstrated by an ever-increasing number of studies, abundant cheap and easily available starting materials and versatile easy synthesis methods have been developed for the preparation of CDs. However, their low yield is the main limitation for the application of CDs in agriculture. Besides this, due to the abundant hydrophilic groups on their surface, it is difficult to obtain CDs as a solid powder, limiting their storage and longdistance transportation prospects. Therefore, there is great demand for the preparation of solid-state CDs in a higher yield. (2) Most studies on the effects of CDs on plant focus on the growth or resistance of plants, while few efforts have been devoted to the quality of crops. In addition, studies on the systematic effect of CDs on different biological species (microorganisms, aquatic organisms, insects, etc.) and their fate in the environment would greatly improve our knowledge about the biological effects of CDs and their applications in agriculture. (3) The excellent photoluminescence of CDs, which is mainly employed to detect and degrade contaminants in the environment, ${ }^{82-84}$ is rarely involved in their applications in plants, except for photosynthesis, whereas, it is unknown whether the function of CDs on plants depends on their photoluminescence, in terms of quantum yield, emission wavelength, etc. (4) The easy surface functionalization of CDs suggests that they can act as a promising deliverer of specific molecules into plants, such as pesticides, nutrients, plant growth regulators, etc.

\section{Conflicts of interest}

There are no conflicts to declare.

\section{Acknowledgements}

The present work was supported by the National Natural Science Foundation of China (Grant No. 21571067 and 21671070). 
The plant pattern diagram in Scheme 1 was provided by https:// www.qianqianhua.com.

\section{References}

1 F. Pulizzi, Nat. Nanotechnol., 2019, 14, 507.

2 G. V. Lowry, A. Avellan and L. M. Gilbertson, Nat. Nanotechnol., 2019, 14, 517-522.

3 M. A. Beketov, B. J. Kefford, R. B. Schäfer and M. Liess, Proc. Natl. Acad. Sci. U. S. A., 2013, 110, 11039.

4 D. Goulson, J. Appl. Ecol., 2013, 50, 977-987.

5 C. Zhao, B. Liu, S. Piao, X. Wang, D. B. Lobell, Y. Huang, M. Huang, Y. Yao, S. Bassu, P. Ciais, J.-L. Durand, J. Elliott, F. Ewert, I. A. Janssens, T. Li, E. Lin, Q. Liu, P. Martre, C. Müller, S. Peng, J. Peñuelas, A. C. Ruane, D. Wallach, T. Wang, D. Wu, Z. Liu, Y. Zhu, Z. Zhu and S. Asseng, Proc. Natl. Acad. Sci. U. S. A., 2017, 114, 9326.

6 J. P. Giraldo, H. Wu, G. M. Newkirk and S. Kruss, Nat. Nanotechnol., 2019, 14, 541-553.

7 O. Zaytseva, G. J. C. Neumann and B. T. I. Agriculture, Chem. Biol. Technol. Agric., 2016, 3, 17.

8 Y. Li, Q. Jin, D. Yang and J. Cui, J. Agric. Food Chem., 2018, 66, 4013-4021.

9 R. Prasad, A. Bhattacharyya and Q. D. Nguyen, Front. Microbiol., 2017, 8, 1014.

10 P. Solanki, A. Bhargava, H. Chhipa, N. Jain and J. Panwar, in Nanotechnologies in Food and Agriculture, ed. M. Rai, C. Ribeiro, L. Mattoso and N. Duran, Springer International Publishing, Cham, 2015, pp. 81-101, DOI: 10.1007/978-3319-14024-7_4.

11 M. Nuruzzaman, M. M. Rahman, Y. Liu and R. Naidu, J. Agric. Food Chem., 2016, 64, 1447-1483.

12 Y. Li, D. Yang and J. Cui, RSC Adv., 2017, 7, 38853-38860.

13 C. G. Athanassiou, N. G. Kavallieratos, G. Benelli, D. Losic, P. Usha Rani and N. Desneux, J. Pestic. Sci., 2018, 91, 1-15.

$14 \mathrm{H}$. Wu, N. Tito and J. P. Giraldo, ACS Nano, 2017, 11, 11283-11297.

15 K. Bhattacharya, S. P. Mukherjee, A. Gallud, S. C. Burkert, S. Bistarelli, S. Bellucci, M. Bottini, A. Star and B. Fadeel, Nanomedicine, 2016, 12, 333-351.

16 D. Chen, C. A. Dougherty, K. Zhu and H. Hong, J. Controlled Release, 2015, 210, 230-245.

17 A. Mukherjee, S. Majumdar, A. D. Servin, L. Pagano, O. P. Dhankher and J. C. White, Front. Plant Sci., 2016, 7, 172.

18 T. R. Shojaei, M. A. M. Salleh, M. Tabatabaei, H. Mobli, M. Aghbashlo, S. A. Rashid and T. Tan, in Synthesis, Technology and Applications of Carbon Nanomaterials, ed. S. A. Rashid, R. N. I. Raja Othman and M. Z. Hussein, Elsevier, 2019, pp. 247-277, DOI: 10.1016/B978-0-12-815757-2.00011-5.

19 S. K. Verma, A. K. Das, S. Gantait, V. Kumar and E. Gurel, Sci. Total Environ, 2019, 667, 485-499.

20 A. Mukherjee, S. Majumdar, A. D. Servin, L. Pagano, O. P. Dhankher and J. C. White, Front. Plant Sci., 2016, 7, 172.

21 X. T. Zheng, A. Ananthanarayanan, K. Q. Luo and P. Chen, Small, 2015, 11, 1620-1636.
22 Z. Peng, X. Han, S. Li, A. O. Al-Youbi, A. S. Bashammakh, M. S. El-Shahawi and R. M. Leblanc, Coord. Chem. Rev., 2017, 343, 256-277.

23 M. J. Molaei, Talanta, 2019, 196, 456-478.

24 P. Zuo, X. Lu, Z. Sun, Y. Guo and H. He, Microchim. Acta, 2016, 183, 519-542.

25 S. Qu, X. Wang, Q. Lu, X. Liu and L. Wang, Angew. Chem., Int. Ed., 2012, 51, 12215-12218.

26 H. Wang, M. Zhang, Y. Song, H. Li, H. Huang, M. Shao, Y. Liu and Z. Kang, Carbon, 2018, 136, 94-102.

27 L.-X. Su, X.-L. Ma, K.-K. Zhao, C.-L. Shen, Q. Lou, D.-M. Yin and C.-X. Shan, ACS Omega, 2018, 3, 17770-17777.

28 H. Li, J. Huang, F. Lu, Y. Liu, Y. Song, Y. Sun, J. Zhong, H. Huang, Y. Wang, S. Li, Y. Lifshitz, S.-T. Lee and Z. Kang, ACS Appl. Bio Mater., 2018, 1, 663-672.

29 H. Wang, H. Li, M. Zhang, Y. Song, J. Huang, H. Huang, M. Shao, Y. Liu and Z. Kang, ACS Appl. Mater. Interfaces, 2018, 10, 16308-16314.

30 S. H. Schwartz, B. Hendrix, P. Hoffer, R. A. Sanders and W. Zheng, bioRxiv, Biochem., 2019, 722595, DOI: 10.1101/ 722595.

31 Z. Yao, Z. Lai, C. Chen, S. Xiao and P. Yang, Analyst, 2019, 144, 3685-3690.

32 S. Zhu, Y. Song, X. Zhao, J. Shao, J. Zhang and B. Yang, Nano Res., 2015, 8, 355-381.

33 W. Li, Y. Zheng, H. Zhang, Z. Liu, W. Su, S. Chen, Y. Liu, J. Zhuang and B. Lei, ACS Appl. Mater. Interfaces, 2016, 8, 19939-19945.

34 J. Chen, R. Dou, Z. Yang, X. Wang, C. Mao, X. Gao and L. Wang, Nanotoxicology, 2016, 10, 818-828.

35 S. Tripathi and S. Sarkar, Appl. Nanosci., 2015, 5, 609-616.

36 M. Zhang, L. Hu, H. Wang, Y. Song, Y. Liu, H. Li, M. Shao, H. Huang and Z. Kang, Nanoscale, 2018, 10, 12734-12742.

37 A. Loukanov, P. Mladenova, S. Toshev, A. Karailiev, E. Ustinovich and S. Nakabayashi, Microsc. Res. Tech., 2018, 81, 1541-1547.

38 K. Qian, H. Guo, G. Chen, C. Ma and B. Xing, Sci. Rep., 2018, 8, 7991.

39 Y. Song, D. Feng, W. Shi, X. Li and H. Ma, Talanta, 2013, 116, 237-244.

40 A. Wang, F. Kang, Z. Wang, Q. Shao, Z. Li, G. Zhu, J. Lu and Y. Y. Li, Adv. Sustainable Syst., 2019, 3, 1800132.

41 D. Chakravarty, M. B. Erande and D. J. Late, J. Sci. Food Agric., 2015, 95, 2772-2778.

42 S. Tripathi, S. Kapri, A. Datta and S. Bhattacharyya, $R S C$ Adv., 2016, 6, 43864-43873.

43 Y. Zheng, H. Zhang, W. Li, Y. Liu, X. Zhang, H. Liu and B. Lei, $R S C A d v$., 2017, 7, 33459-33465.

44 Y. Zheng, G. Xie, X. Zhang, Z. Chen, Y. Cai, W. Yu, H. Liu, J. Shan, R. Li, Y. Liu and B. Lei, ACS Omega, 2017, 2, 3958-3965.

45 H. Li, J. Huang, Y. Liu, F. Lu, J. Zhong, Y. Wang, S. Li, Y. Lifshitz, S.-T. Lee and Z. Kang, Nano Res., 2019, 12, 1585-1593.

46 J. Chen, B. Liu, Z. Yang, J. Qu, H. Xun, R. Dou, X. Gao and L. Wang, Environ. Sci.: Nano, 2018, 5, 2672-2685.

47 D. R. Ort, S. S. Merchant, J. Alric, A. Barkan, R. E. Blankenship, R. Bock, R. Croce, M. R. Hanson, J. M. Hibberd, 
S. P. Long, T. A. Moore, J. Moroney, K. K. Niyogi, M. A. J. Parry, P. P. Peralta-Yahya, R. C. Prince, K. E. Redding, M. H. Spalding, K. J. van Wijk, W. F. J. Vermaas, S. von Caemmerer, A. P. M. Weber, T. O. Yeates, J. S. Yuan and X. G. Zhu, Proc. Natl. Acad. Sci. U. S. A., 2015, 112, 8529.

48 A. V. Barker and D. J. Pilbeam, Handbook of plant nutrition, CRC press, Boca Raton, 2nd edn, 2015.

49 L. Király, B. Barna and Z. Király, J. Phytopathol., 2007, 155, 385-396.

50 S. J. Roy, E. J. Tucker and M. Tester, Curr. Opin. Plant Biol., 2011, 14, 232-239.

51 A. R. Fox, G. Soto, C. Valverde, D. Russo, A. Lagares Jr, Á. Zorreguieta, K. Alleva, C. Pascuan, R. Frare, J. MercadoBlanco, R. Dixon and N. D. Ayub, Environ. Microbiol., 2016, 18, 3522-3534.

52 A. Segalla, I. Szabò, P. Costantini and G. M. Giacometti, J. Chem. Inf. Model., 2005, 45, 1691-1700.

53 M. Paul, Ann. Bot., 2012, 111, ix.

54 L. Cao, S. Sahu, P. Anilkumar, C. E. Bunker, J. Xu, K. A. S. Fernando, P. Wang, E. A. Guliants, K. N. Tackett and Y.-P. Sun, J. Am. Chem. Soc., 2011, 133, 4754-4757.

55 S. Mitra, S. Chandra, P. Patra, P. Pramanik and A. Goswami, J. Mater. Chem., 2011, 21, 17638-17641.

56 S. N. Baker and G. A. Baker, Angew. Chem., Int. Ed., 2010, 49, 6726-6744.

57 H. Li, Z. Kang, Y. Liu and S.-T. Lee, J. Mater. Chem., 2012, 22, 24230-24253.

58 Y. Gong and J. Zhao, J. Agric. Food Chem., 2018, 66, 9159-9161.

59 Y. Wang and A. Hu, J. Mater. Chem. C, 2014, 2, 6921-6939.

60 S. Chandra, S. Pradhan, S. Mitra, P. Patra, A. Bhattacharya, P. Pramanik and A. Goswami, Nanoscale, 2014, 6, 3647-3655.

61 W. Li, S. Wu, H. Zhang, X. Zhang, J. Zhuang, C. Hu, Y. Liu, B. Lei, L. Ma and X. Wang, Adv. Funct. Mater., 2018, 28, 1804004.

62 C. Huang, T. Xia, J. Niu, Y. Yang, S. Lin, X. Wang, G. Yang, L. Mao and B. Xing, Angew. Chem., Int. Ed., 2018, 57, 9759-9763.

63 M. Zhang, H. Wang, Y. Song, H. Huang, M. Shao, Y. Liu, H. Li and Z. Kang, ACS Appl. Bio Mater., 2018, 1, 894-902.

64 L. Sai, S. Liu, X. Qian, Y. Yu and X. Xu, Colloids Surf., B, 2018, 169, 422-428.

65 G. R. Cramer, K. Urano, S. Delrot, M. Pezzotti and K. Shinozaki, BMC Plant Biol., 2011, 11, 163.
66 F. K. Choudhury, R. M. Rivero, E. Blumwald and R. Mittler, Plant J., 2017, 90, 856-867.

67 S. S. Gill and N. Tuteja, Plant Physiol. Biochem., 2010, 48, 909-930.

68 S. Zhao, M. Lan, X. Zhu, H. Xue, T.-W. Ng, X. Meng, C.-S. Lee, P. Wang and W. Zhang, ACS Appl. Mater. Interfaces, 2015, 7, 17054-17060.

69 B. Das, P. Dadhich, P. Pal, P. K. Srivas, K. Bankoti and S. Dhara, J. Mater. Chem. B, 2014, 2, 6839-6847.

70 H. Wang, Y. Xie, X. Na, J. Bi, S. Liu, L. Zhang and M. Tan, Food Chem., 2019, 286, 405-412.

71 Y. Chong, C. Ge, G. Fang, X. Tian, X. Ma, T. Wen, W. G. Wamer, C. Chen, Z. Chai and J.-J. Yin, ACS Nano, 2016, 10, 8690-8699.

72 F. Li, T. Li, C. Sun, J. Xia, Y. Jiao and H. Xu, Angew. Chem., Int. Ed., 2017, 56, 9910-9914.

73 L. Xiao, H. Guo, S. Wang, J. Li, Y. Wang and B. Xing, Environ. Sci.: Nano, 2019, 6, 1493-1506.

74 J. Li, L. Xiao, Y. Cheng, Y. Cheng, Y. Wang, X. Wang and L. Ding, Chemosphere, 2019, 236, 124385.

75 B. B. Bohlool, J. K. Ladha, D. P. Garrity and T. George, Plant Soil, 1992, 141, 1-11.

76 B. M. Hoffman, D. Lukoyanov, Z.-Y. Yang, D. R. Dean and L. C. Seefeldt, Chem. Rev., 2014, 114, 4041-4062.

77 J. Kim and D. C. Rees, Biochemistry, 1994, 33, 389-397.

78 A. Servin, W. Elmer, A. Mukherjee, R. De la Torre-Roche, H. Hamdi, J. C. White, P. Bindraban and C. Dimkpa, J. Nanopart. Res., 2015, 17, 92.

79 J. Liu, S. Lu, Q. Tang, K. Zhang, W. Yu, H. Sun and B. Yang, Nanoscale, 2017, 9, 7135-7142.

80 H. Li, J. Huang, Y. Song, M. Zhang, H. Wang, F. Lu, H. Huang, Y. Liu, X. Dai, Z. Gu, Z. Yang, R. Zhou and Z. Kang, ACS Appl. Mater. Interfaces, 2018, 10, 26936-26946.

81 C. Zhu, H. Li, H. Wang, B. Yao, H. Huang, Y. Liu and Z. Kang, Small, 2019, 15, 1900007.

82 A. Bhati, S. R. Anand, Gunture, A. K. Garg, P. Khare and S. K. Sonkar, ACS Sustainable Chem. Eng., 2018, 6, 9246-9256.

83 H. Wang, J. Zhuang, D. Velado, Z. Wei, H. Matsui and S. Zhou, ACS Appl. Mater. Interfaces, 2015, 7, 27703-27712.

84 H. Safardoust-Hojaghan and M. Salavati-Niasari, J. Cleaner Prod., 2017, 148, 31-36. 